\title{
O IMPACTO DA INTERNACIONALIZAÇÃO NOS ESQUEMAS INTERPRETATIVOS DOS DIRIGENTES DO BANCO BAMERINDUS
}

\author{
Clóvis L. Machado-da-Silva \\ Professor de Estratégia, Mudança e Análise Organizacional do Centro de Pesquisa e Pós-Graduação \\ em Administração da Universidade Federal do Paraná. \\ E-mail: clms@ceppad.ufpr.br \\ Bruno H. Rocha Fernandes \\ Professor do Centro de Pesquisa e Pós-Graduação em Administração da Universidade Federal do Paraná.
}

\section{RESUMO}

O objetivo do presente estudo de caso foi verificar o impacto do processo de internacionalização do Banco Bamerindus sobre os esquemas interpretativos dos seus dirigentes no período compreendido entre 1989 e 1995. 0 estudo de caso, realizado com base em análise longitudinal dos dados e em uso de diferentes fontes de evidência com 0 apoio da técnica de triangulação, revela que o impacto da internacionalização foi de natureza incremental, o que não confirma estudos anteriores sobre 0 tema. Algumas hipóteses foram levantadas para explicar tal resultado: o pouco tempo de envolvimento internacional do Bamerindus; a evolução incremental da internacionalização; a existência prévia de alguns valores coerentes com valores compartilhados no exterior; e as peculiaridades do contexto institucional brasileiro após longa história de alta inflação que dificultaram a assimilação de valores e crenças disponibilizados pela experiência internacional.

\section{ABSTRACT}

The aim of the present case study is to verify the impact of Bamerindus Bank internationalization process in relation to Bamerindus directors interpretive schemes during the 1989-1995 period. This case study was oriented by a longitudinal perspective of data analysis and has used different sources of evidence through the triangulation technique support. It unveils that the impact of the internationalization has been rather incremental, and does not confirm previous findings concerning this theme. Some hypotheses were raised in order to explain such a result: Bamerindus short-time experience in international affairs; a just incremental international evolution; previous existence of values coherent with some values shared abroad; and, last but not least, Brazilian peculiar institutional context and mind set secondary to a very long succession of failed and frustrating plans to overcome a tremendous tridecennial period of inflation.

\section{PALAVRAS-CHAVE}

Mudança organizacional, internacionalização de empresas, esquemas interpretativos, cultura organizacional, ambiente organizacional.

KEY WORDS

Organizational change, internationalization of the firm, interpretive schemes, organizational culture, organizational environment. 


\section{INTRODUÇÃO}

Uma das características marcantes no ambiente empresarial do final deste século é a crescente globalização da economia. O desenvolvimento de novas tecnologias nas áreas de telecomunicação e informática, a desregulamentação da atividade financeira, os acordos de remoção mútua de barreiras comerciais entre países, com o conseqüente incremento do comércio internacional, aliados à necessidade de as empresas se tornarem cada vez mais competitivas, vêm estabelecendo um contexto ao mesmo tempo desafiador e propício para as organizações ampliarem seu campo de atuação, particularmente por meio de estratégias de internacionalização.

A internacionalização, processo crescente e continuado de envolvimento de uma empresa em operações em países fora de sua base de origem (Goulart, Arruda e Brasil, 1994), é fenômeno particularmente presente no Brasil nos últimos anos. A partir da abertura da economia no início dos anos 90, as empresas brasileiras não apenas passaram a sofrer o impacto do aumento da concorrência externa, mas também perceberam a importância de ampliar seu mercado pela adoção de estratégias de internacionalização, utilizando vantagens competitivas existentes ou passíveis de serem desenvolvidas.

O envolvimento internacional de uma empresa implica mudança organizacional. A internacionalização parece afetar a organização como um todo, atingindo dimensões como tamanho, escopo, missão, princípios de atuação, natureza do trabalho administrativo, valores dominantes e normas (Melin, 1992). Sua natureza é tal que forma um círculo virtuoso: maior grau de internacionalização implica maior conhecimento do mercado externo, que, por sua vez, leva a envolvimento ainda maior e, portanto, a aprofundamento no processo (Arruda, Goulart e Brasil, 1994).

Bartlett e Ghoshal (1992) afirmam que o processo de internacionalização pode acarretar mudanças em três níveis da organização: na estrutura e responsabilidades formais (anatomia), nos relacionamentos e processos interpessoais (fisiologia) e nas atitudes e mentalidade ${ }^{1}$ dos indivíduos (psicologia). Dentre essas dimensões, a psicologia vem sendo tratada com interesse especial. Perlmutter (1969) julga tão importante o mind set da organização que chega a considerá-lo a característica distintiva da internacionalização: "quanto mais alguém penetra na realidade das multinacionais, mais descobre a necessidade de dar peso ao modo como os executivos pensam e fazem negócios ao longo do mundo" (p. 11).

O pensar e o fazer dos executivos dependem de seus esquemas interpretativos, isto é, do conjunto de idéias, valores e crenças que dá ordem e coerência às estruturas e aos sistemas em uma organização (Machado-da-Silva e Fonseca, 1995; Hinings e Greenwood, 1989). Crenças e valores compartilhados em uma empresa parecem ser, portanto, fundamentais para o delineamento de suas estratégias de ação. Com base nesse pressuposto, procura-se, no presente trabalho, examinar o impacto do processo de internacionalização nos esquemas interpretativos de dirigentes organizacionais. A fim de verificar essa relação em uma situação concreta, selecionou-se o Banco Bamerindus, um dos maiores bancos de varejo do país. Os critérios estabelecidos para essa escolha incluem a significativa expansão internacional do Bamerindus a partir de 1990, o que o tornou um dos líderes nacionais nas atividades de câmbio e emissões de títulos no exterior. Por sua vez, o direcionamento do estudo para uma organização do setor bancário deu-se pela constatação de que a internacionalização recente de bancos brasileiros não vem sendo objeto de investigação sistemática na área de estudos organizacionais no país.

\section{BASE TEÓRICO-EMPÍRICA}

Sobre o tema mudança organizacional, muito se tem escrito nas últimas décadas. Embora utilizem terminologias distintas, os autores costumam enfatizar dois tipos de mudança: o incremental e o estratégico. Pela mudança incremental pretende-se representar mudanças localizadas, sem que se envolva a organização em sua totalidade. Já a mudança estratégica refere-se a mudanças amplas que atingem a organização como um todo. Nas mudanças estratégicas estão em jogo dimensões como tamanho, escopo, missão, valores e normas; enfim, todo o espectro que caracteriza a atividade da organização.

Barr, Stimpert e Huff (1992) apontam, na literatura especializada, duas situações em que pode ocorrer mudança nos modelos mentais dos indivíduos e, conseqüentemente, no aprendizado organizacional. $\mathrm{O}$ aprendizado de baixo grau implica modificações mais de comportamento do que de entendimento, o que significa transformações incrementais ou ajus- 
tes menores nas interpretações existentes. O aprendizado de alto grau, por sua vez, envolve a reestruturação dos modelos mentais dos membros organizacionais e resulta em mudanças significativas no entendimento.

Com uma linha similar de raciocínio, Hinings e Greenwood (1989) caracterizam a mudança em função de sua relação com as crenças e os valores compartilhados na organização. Os autores utilizam o conceito de arquétipos organizacionais, que consistem em agrupamentos de estruturas prescritas e interações emergentes que recebem ordem ou coerência de um conjunto de idéias, valores e crenças, isto é, dos esquemas interpretativos. Quaisquer práticas que surgem em uma organização, como implantar plano de carreira, planejamento estratégico, círculos de controle de qualidade ou expansão internacional, devem ser confrontadas com as crenças e valores prevalecentes para se efetivarem. Como conseqüência, dois tipos de mudança organizacional são possíveis: o ajustamento (ou mudança incremental) de estruturas e processos para alcançar uma coerência maior dentro de um mesmo arquétipo e a reorientação (ou mudança estratégica), transformações estruturais ou sistêmicas que acarretam movimento de um arquétipo para outro.

Mudanças estratégicas e incrementais não precisam ser vistas necessariamente em uma perspectiva dicotômica (Kanter et al., 1992). Pequenas mudanças quantitativas em uma mesma direção (mudanças com m minúsculo ou small-c change) vão se acumulando ao longo do tempo de tal forma que podem resultar em mudança qualitativa (Mudança com M maiúsculo ou capital-C Change).

A reorientação dos esquemas interpretativos dos dirigentes organizacionais ocorre geralmente pela força de pressões ambientais significativas. Mudanças fundamentais no ambiente externo podem levar os esquemas interpretativos correntes a perder suporte ambiental e, desse modo, ter sua legitimidade questionada. Fica, então, um contexto favorável à ascensão de novos tipos de líderes que respondam às novas circunstâncias ambientais e representem a emergência de novos esquemas interpretativos.

Para entendimento mais adequado da interação entre pressões ambientais e esquemas interpretativos, torna-se necessário considerar tratamentos alternativos ao enfoque da escolha estratégica, usualmente utilizado para a análise do ambiente externo das organizações.
Uma abordagem alternativa é proposta por Machadoda-Silva e Fonseca (1996a), que defendem o uso de uma perspectiva integrada a partir da interseção entre teoria econômica e teoria institucional. Nessa perspectiva, os autores articulam dois conceitos, "enquanto facetas de uma mesma dimensão" (p. 214), para entender a dinâmica da mudança organizacional: as noções de ambiente técnico e ambiente institucional. Ambientes técnicos são "aqueles cuja dinâmica de funcionamento se desencadeia por meio da troca de bens $e$ serviços, de modo que as organizações que nele se incluem são avaliadas pelo processamento tecnicamente eficiente do trabalho" (p. 214). Os ambientes institucionais, por sua vez, caracterizam-se "pela elaboração e difusão de regras e procedimentos que proporcionam às organizações legitimidade e suporte contextual (...). Sob condições de incerteza, as organizações sujeitam-se a requerimentos governamentais, copiam estruturas e práticas, ou implementam medidas genericamente aceitas em redes profissionais" (p. 214). Tanto o ambiente técnico quanto o ambiente institucional compreendem níveis de análise: local, regional, nacional e internacional. As organizações, diante da necessidade de definir estratégias de ação, orientam-se pelo contexto institucional no nível que mais se coaduna com sua lógica interior, isto é, com os esquemas interpretativos de seus dirigentes. "Os indivíduos interpretam e definem ações conforme os significados que atribuem à realidade na qual se encontram inseridos" (p. 218). Define-se, assim, o contexto institucional de referência do grupo de dirigentes que detém o domínio da organização. Obviamente, "a organização mais competitiva é aquela que absorve as concepções subjacentes à sustentação do padrão de concorrência internacional e as aplica na definição de estratégias coerentes de ação" (p. 219). No entanto, uma organização que detenha uma trajetória de sucesso com base em estratégias alinhadas com um contexto institucional nacional, por exemplo, pode encontrar dificuldades em adotar práticas legitimadas em um contexto institucional mais amplo, em especial se estas implicarem mudanças estratégicas. Apenas em condições de grandes dificuldades ou de crise, torna-se possível implementar mudanças fundamentais que impliquem reorientação dos esquemas interpretativos da organização. Em situação de desempenho organizacional satisfatório, a tendência é a adoção de mudanças de caráter incremental, coerentes com a lógica interna da em- 
presa. "Sob esse prisma, a competitividade vinculase a regras externamente aceitas e compartilhadas de acordo com o quadro de referência cultural e relacional da organização" (p. 219).

A internacionalização vem sendo tratada quer como estratégia empresarial, quer como pressão ambiental geradora de mudança estratégica nas organizações. De acordo com a literatura especializada, à medida que a empresa se aprofunda no processo de internacionalização, tendem a ocorrer mudanças em diversas dimensões organizacionais, ou seja, na estrutura, nos processos e na cultura. No que interessa ao presente estudo, a questão básica consiste em verificar em que extensão afeta os esquemas interpretativos dos dirigentes, tendo em vista que, ao se constituir um processo de aprendizagem organizacional, vincula-se a crenças e valores compartilhados (Melin, 1992).

A aprendizagem provocada pela internacionalização ocorre mediante processo de tentativa e erro que, a partir das vantagens competitivas adquiridas no país de origem ou na comercialização internacional de produtos e serviços, se reflete no próprio desenvolvimento e crescimento da empresa no mercado local (Goulart, Arruda e Brasil, 1994).

Também Johanson e Vahlne (1990) apresentam a internacionalização como processo seqüencial de aprendizagem, que vai desde a atividade de exportação até o estabelecimento de uma unidade de produção no exterior. Nessa dinâmica, estabelecer uma planta no exterior cumpre a função essencial de desenvolver conhecimento experimental das diferenças entre os países em termos de língua, cultura, educação e legislação.

\section{A SITUAÇÃO EM ESTUDO}

O Banco Bamerindus tinha sede em Curitiba, Paraná. Possuía cerca de 1.200 agências e 25.000 empregados, sendo, no período compreendido por esta pesquisa (1989 a 1995), o terceiro maior banco privado nacional em número de agências.

O primeiro passo do Bamerindus no campo internacional ocorreu no final de 1982, quando, seguindo a política governamental do momento, estabeleceu uma agência em Nova York. Na ocasião, havia forte estímulo para a abertura de agências no exterior como forma de obtenção de financiamento para a dívida externa e para o desenvolvimento do país. Até meados da década de 80, a unidade de Nova York permaneceu sendo a única iniciativa do Banco no exterior. As opera- ções da agência, porém, permaneciam à margem das operações do Bamerindus e prestavam-se somente para a captação de dinheiro a baixo custo.

A segunda unidade internacional do Bamerindus foi instituída nas Ilhas Cayman. A atratividade dessas ilhas advém de sua condição de paraíso fiscal puro, com carga tributária inexistente, liberdade cambial, igualdade de tratamento a estrangeiros e cidadãos locais e confidencialidade internacional.

Até esse momento, as agências internacionais, a área de câmbio e as operações domésticas constituíam compartimentos estanques, com fraco inter-relacionamento. A partir de 1990, o Bamerindus procurou estabelecer uma estratégia integrada para sua atuação no exterior. A estratégia teve como pressuposto que a área internacional deveria integrar-se à área doméstica.

O plano do Bamerindus consistiu, basicamente, em estabelecer uma rede internacional de negócios sem o custo de uma rede de agências. Nesse sentido, procurou ocupar as "esquinas do mundo" 2 , grandes mercados que centralizam as decisões mundiais do mercado financeiro: Nova York, Londres e Hong Kong integram essa categoria. Além disso, o Bamerindus também procurou estar presente no Mercosul, pela sua importância para o Brasil.

A estratégia começou por reorganizar as unidades internacionais existentes. A agência de Nova York foi estruturada como um sistema de pagamentos e recebimentos, centralizando todas as operações internacionais. A escolha da cidade deveu-se à importância do mercado local e ao fato de que o Brasil é um país no qual as transações financeiras e comerciais são feitas predominantemente em dólares. Além disso, a desregulamentação do mercado financeiro e a tecnologia permitem realizar uma transação em um lugar e contabilizá-la em outro. Por exemplo, "uma linha de crédito negociada na Suécia pode ser facilmente contabilizada em Nova York".

O passo seguinte foi a inauguração, em 1991, de um escritório de representação em Londres. O escritório passou a concentrar todos os relacionamentos do Bamerindus com o mercado bancário europeu. Suas atividades básicas consistiram em captação e prestação de serviços de comércio exterior para empresas brasileiras, como cobranças e recebimentos. Posteriormente, o Banco estabeleceu duas financeiras nessa cidade.

Em relação ao Mercosul, a estratégia do Bamerindus foi instalar um escritório de representação em Buenos Aires. O escritório tinha como objetivo dar 
apoio ao comércio exterior do Brasil na região, ampliar relações com bancos argentinos e cobrir os demais países do Mercosul.

O Bamerindus começou a operar na terceira "esquina do mundo", Hong Kong, no segundo semestre de 1994. O objetivo do escritório era representar o Banco na Ásia, consistindo em uma aposta na abertura do mercado chinês. Entre outras operações, o escritório procurava negociar linhas de crédito com o Eximbank e intermediar a vinda de empresas coreanas para o Brasil.

Em 1995, o Bamerindus inaugurou uma subsidiária em Luxemburgo. A forma legal escolhida justifica-se pela possibilidade que as subsidiárias têm de captar recursos de residentes no exterior. A subsidiária também é, na Europa, uma cabeça-de-ponte que garante a presença do Banco no continente após a consolidação da Comunidade Econômica Européia.

\section{PROCEDIMENTOS PARA COLETA E CODIFICAÇÃO DOS DADOS}

Após o breve histórico sobre o processo de internacionalização do Banco Bamerindus, cabe mencionar os procedimentos utilizados para a coleta e a codificação dos dados relativamente às duas categorias analíticas em estudo: grau de internacionalização e esquemas interpretativos do grupo dirigente. O roteiro para a coleta de dados consistiu, inicialmente, em aferir o grau de internacionalização (GDI) do Bamerindus ao longo do período compreendido entre 1989 e 1995. Para tanto, utilizou-se uma adaptação da escala de Sullivan (1994) para o setor bancário. A escala procura avaliar o GDI de uma empresa considerando três dimensões: o desempenho (o que ocorre no exterior), a estrutura (quais recursos estão no exterior) e a atitude (qual é a orientação do grupo dirigente com relação às operações internacionais). O GDI é expresso pela fórmula:

$$
G D I=A E A T+P I P B T+P E P T+D P O I+E I D,
$$

onde:

AEAT: ativos gerados por meio de operações no exterior em relação aos ativos totais do Banco;

PIPBT: número de produtos ou serviços internacionais oferecidos pelo Banco em relação ao número total de produtos que os grandes bancos transnacionais oferecem;

PEPT: patrimônio do Banco no exterior em relação ao patrimônio total;

DPOI: dispersão psíquica das operações internacionais. Atribui-se pontuação de 0,1 pela presença de uma ou mais unidades organizacionais em cada uma das dez zonas psíquicas mundiais; ${ }^{3}$

EID: experiência internacional dos dirigentes. É mensurada em termos da proporção do tempo de trabalho com atividades internacionais em relação ao tempo de carreira.

A seguir, foram construídos 14 mapas causais, um para cada relatório semestral da administração do Bamerindus no período. Para a construção dos mapas causais, o primeiro passo foi identificar os conceitos nos referidos relatórios. As relações entre esses conceitos foram classificadas em uma das nove categorias de codificação desenvolvidas por Huff, Narapareddy e Fletcher (1990), apresentadas no Quadro 1. Os mapas foram construídos vinculando-se os conceitos por meio de setas assinaladas com a categoria de codificação correspondente ao tipo de relação.

Para exemplificar o procedimento, apresenta-se um parágrafo do relatório da administração de 31 de dezembro de 1993:

"Não obstante a inflação extremamente alta de $2.567 \%$ (IGP-M), o Produto Interno Bruto (PIB) cresceu cerca de 4,5\% em relação a 1992, revertendo o ciclo recessivo que perdurava desde 1990. Contribuíram para esta performance o bom desempenho das indústrias, mesmo que setorizado, o ingresso de capital externo, o positivo encaminhamento da renegociação da dívida externa e o crescimento das exportações."

O parágrafo é codificado como se segue:

Os conceitos identificados nos mapas causais foram classificados nas seguintes categorias: conceitos internacionais; postura frente ao risco; importância atribuída à tecnologia; patriotismo; valorização do pessoal; postura inovadora, criativa e arrojada; orientação para marketing; produtividade e eficiência; conceitos utilizados para entendimento da conjuntura político-econômica e outros. A se-

Quadro 1 - Categorias de codificação

\begin{tabular}{|c|c|}
\hline Símbolo & Definição \\
\hline$I+I$ & afeta positivamente \\
\hline$I-I$ & afeta negativamente \\
\hline$/ \Theta /$ & não atrapalha, não evita, não é prejudicial \\
\hline$/ \oplus /$ & não ajuda, não estimula, não é benéfico \\
\hline la/ & $\begin{array}{l}\text { pode, ou não, estar relacionado a, afeta de } \\
\text { modo indeterminado }\end{array}$ \\
\hline$/ \mathrm{m} /$ & afeta de algum modo \\
\hline lo/ & $\begin{array}{l}\text { não importa para, não tem efeito sobre, } \\
\text { não tem relação com }\end{array}$ \\
\hline$I=I$ & é equivalente a, é definido como \\
\hline le/ & é um exemplo de, é um membro de \\
\hline
\end{tabular}


guir, foram verificados os valores manifestos nessas categorias. Os valores assim apurados foram confrontados com as estratégias do Bamerindus no período em estudo. O objetivo foi verificar se as estratégias de fato refletem os valores mencionados. Por fim, avaliou-se a variação dos valores com o passar do tempo, o que se fez considerando-se a frequiência dos conceitos dentro das categorias em cada relatório.

A análise dos mapas causais, aliada a indicadores de dimensões organizacionais (tais como arranjo formal, estratégias, centralização, estilo de liderança, processo de tomada de decisão e forma de comunicação), serviu de base para elaborar o roteiro de entrevistas semi-estruturadas com dirigentes. A triangulação dos resultados das entrevistas e dos mapas causais permitiu a avaliação dos esquemas interpretativos do grupo dirigente.

O superintendente do Bamerindus e os diretores das áreas funcionais, perfazendo um total de oito pessoas, constituem a população considerada para entrevista neste trabalho, uma vez que representam a alta administração do Banco no período em estudo. Mediante a técnica de amostragem intencional, foram selecionados cinco dirigentes: o Superintendente e os diretores de quatro áreas fins (Diretor da Unidade Internacional, Diretor de Finanças, Diretor de Operações e Diretor de Produto). A escolha desses diretores deu-se pela maior possibilidade de impacto do processo de internacionalização nessas áreas funcionais. Quando da amostragem, não se julgou necessário entrevistar os três diretores ligados à área meio da empresa. Durante o desenvolvimento do estudo, tal decisão revelou-se adequada em face do alto grau de consistência das entrevistas entre si e com os mapas causais dos relatórios da administração.

\section{AS CATEGORIAS ANALÍTICAS EM ESTUDO}

Conforme já se mencionou anteriormente, o processo de internacionalização do Bamerindus foi analisado no período compreendido entre 1989 e 1995. A razão para se iniciar em 1989 prende-se ao fato de que, até essa data, as operações internacionais funcionavam de forma autônoma e desvinculada do restante das operações do Bamerindus e mesmo das operações da área de câmbio. Portanto o que foi realizado no exterior antes de 1989 não deveria, em princípio, afetar as estratégias e, ainda menos, os esquemas interpretativos do grupo dirigente do Banco.

A partir de 1989, a estratégia de expansão internacional do Bamerindus começou a alterar seu grau de internacionalização (GDI) em suas três dimensões: desempenho, estrutura e atitude.

O GDI do Banco foi calculado a partir do somatório dos cinco componentes (AEAT, PIPBT, PEPT, DPOI e EID) e é apresentado na Tabela 1. O intervalo de variação do GDI situa-se entre 0,0 e 5,0.

Os resultados demonstraram crescente envolvimento internacional do Banco Bamerindus, mas de natureza incremental. Não houve nenhum salto brusco nos níveis de internacionalização no período.

\section{MAPAS CAUSAIS}

Os mapas causais foram segmentados em áreas específicas, a saber, conjuntura econômica e política; diretrizes do Bamerindus; captação de recursos e operações de crédito; área internacional; infra-estrutura, produtos e serviços e recursos humanos. Os conceitos mencionados nos relatórios da administração e explicitados nos mapas causais foram classificados em 11 categorias, que aparecem na Tabela 2. Para os 14 mapas, indica-se a freqüên-

Tabela 1 - GDI do Bamerindus no período de 1989 a 1995

\begin{tabular}{|l|l|l|l|l|l|l|l|}
\hline & 1989 & 1990 & 1991 & 1992 & 1993 & 1994 & 1995 \\
\hline GDI & 0,62 & 0,67 & 1,03 & 1,34 & 1,48 & 1,73 & 1,92 \\
\hline
\end{tabular}

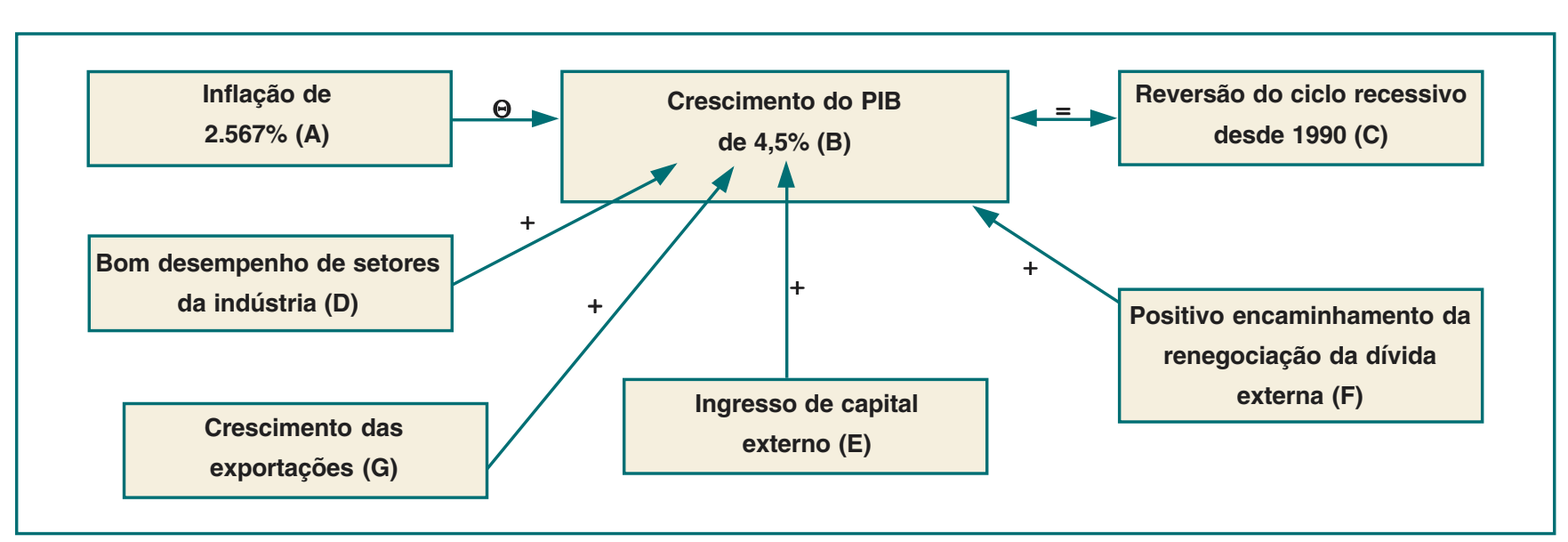


cia com que aparecem os conceitos dentro de cada categoria.

A análise da Tabela 2 sugere o crescimento da importância atribuída à área internacional e o aumento na preocupação com eficiência e produtividade no último ano. Conceitos como postura inovadora, orientação para tecnologia, preocupação com clientes, postura frente ao risco, patriotismo e valorização do pessoal não parecem seguir nenhuma tendência de crescimento ou diminuição. Tais resultados foram avaliados nas entrevistas semiestruturadas com os dirigentes selecionados.

As entrevistas enriqueceram os resultados levantados pela análise dos mapas causais. Por exemplo, na opinião dos diretores, a postura de aversão ao risco, manifestada em termos de seletividade e precaução em atividades de crédito, vem se transformando, como demonstra a preocupação crescente do Banco em incrementar o volume de empréstimos após o Plano Real. Conforme afirmou um diretor: "Com a estabilização da economia a partir do Plano Real nós tivemos que nos preparar para rapidamente conceder crédito. De um momento para outro, tivemos que atu- ar de forma descentralizada para dar vazão às solicitações da nossa clientela".

Da mesma forma, a análise dos componentes organizacionais do Bamerindus reforça os valores identificados por meio dos mapas causais. Um exemplo são as estratégias implementadas pelo Banco no período, que manifestam a orientação para inovação, tecnologia e marketing.

Os esquemas interpretativos foram avaliados mediante os valores identificados com base na triangulação dos diversos instrumentos de pesquisa. Os resultados são apresentados no Quadro 2.

A análise conjunta dos dados sugere que o processo de internacionalização não provocou reorientação nos esquemas interpretativos do grupo dirigente. A sua influência foi de caráter incremental: disponibilizou ferramentas e recursos que contribuíram para melhorar as formas de comunicação, as estratégias, entre outros, mas os valores da organização permaneceram em essência os mesmos. Tal resultado parece contradizer a relação proposta na literatura especializada, em que a internacionalização é considerada como fator de mudança estratégica na organização. A transformação oca-

\begin{tabular}{|c|c|c|c|c|c|c|c|c|c|c|c|c|c|c|}
\hline Conceitos & $06 / 89$ & $12 / 89$ & $06 / 90$ & $12 / 90$ & $06 / 91$ & $12 / 91$ & $06 / 92$ & $12 / 92$ & $06 / 93$ & $12 / 93$ & $06 / 94$ & $12 / 94$ & $06 / 95$ & $12 / 95$ \\
\hline $\begin{array}{l}\text { Conceitos internacionais na } \\
\text { área internacional }\end{array}$ & 0 & 2 & 5 & 23 & 16 & 15 & 12 & 13 & 15 & 16 & 14 & 23 & 22 & 19 \\
\hline $\begin{array}{l}\text { Conceitos internacionais } \\
\text { presentes em outras áreas }\end{array}$ & 1 & 1 & 2 & 1 & 1 & 3 & 4 & 1 & 3 & 4 & 5 & 6 & 9 & 10 \\
\hline $\begin{array}{l}\text { Redução de custos/ } \\
\text { produtividade }\end{array}$ & 6 & 3 & 1 & 1 & 3 & 5 & 1 & 0 & 0 & 0 & 2 & 1 & 3 & 9 \\
\hline $\begin{array}{l}\text { Postura inovadora, } \\
\text { criativa e arrojada }\end{array}$ & 3 & 3 & 0 & 0 & 1 & 1 & 2 & 0 & 1 & 3 & 1 & 2 & 2 & 8 \\
\hline $\begin{array}{l}\text { Preocupação com clientes/ } \\
\text { orientação para marketing }\end{array}$ & 6 & 5 & 9 & 6 & 4 & 6 & 5 & 5 & 4 & 9 & 4 & 5 & 9 & 2 \\
\hline Postura frente ao risco & 2 & 5 & 1 & 3 & 3 & 2 & 1 & 6 & 4 & 0 & 0 & 3 & 0 & 3 \\
\hline Patriotismo & 0 & 2 & 0 & 3 & 0 & 1 & 0 & 0 & 0 & 1 & 0 & 0 & 0 & 0 \\
\hline $\begin{array}{l}\text { Importância atribuída à } \\
\text { tecnologia }\end{array}$ & 2 & 2 & 4 & 3 & 2 & 2 & 2 & 2 & 4 & 3 & 2 & 4 & 2 & 3 \\
\hline Valorização do pessoal & 4 & 8 & 8 & 9 & 5 & 7 & 6 & 6 & 5 & 8 & 7 & 8 & 5 & 4 \\
\hline $\begin{array}{l}\text { Conceitos utilizados para } \\
\text { entendimento da conjuntura }\end{array}$ & 12 & 12 & 26 & 26 & 20 & 15 & 10 & 9 & 12 & 17 & 10 & 20 & 20 & 15 \\
\hline Outros & 9 & 13 & 23 & 8 & 10 & 9 & 11 & 16 & 20 & 17 & 11 & 14 & 15 & 13 \\
\hline Total & 45 & 56 & 79 & 83 & 65 & 66 & 54 & 58 & 68 & 78 & 56 & 76 & 87 & 86 \\
\hline
\end{tabular}


sionada pelo processo de internacionalização nos esquemas interpretativos dos dirigentes do Bamerindus parece aproximar-se do tipo de mudança descrito por Machado-da-Silva e Fonseca (1993, p. 156): "Sustenta-se, deste modo, que os padrões de significado [esquemas interpretativos] sofrem modificações incrementais cujo efeito acumulativo pode desencadear, por ocasião de uma circunstância situacional, redefinições ou transformações das características estruturais da organização ao longo do tempo. (...) sugere-se que a mudança decorre da combinação entre períodos de progressivas alterações incrementais e de impactos ambientais sobre a forma organizacional, e não necessariamente de modificações radicais e descontínuas, como propaga-se na literatura especializada".

\section{BREVE APROFUNDAMENTO DA ANÁLISE E CONSIDERAÇÕES FINAIS}

No presente artigo, procurou-se caracterizar o processo de internacionalização do Banco Bamerindus no período de 1989 a 1995 e, ao mesmo tempo, observar se houve mudança nos esquemas interpretativos do grupo dirigente, mediante a análise dos valores compartilhados. Pôde-se constatar variação incremental quer no grau de internacionalização do Bamerindus, quer nos esquemas interpretativos de seu grupo dirigente.

O caráter incremental da mudança ocasionada pela internacionalização parece evidente quando se consi- dera a ausência de transformação substancial em alguns valores organizacionais, como a postura inovadora, a atitude frente ao risco, a noção de eficiência e de produtividade. Tal constatação, decorrente da análise dos relatórios da administração, foi depois confirmada nas entrevistas com os dirigentes do Banco.

Apontar o processo de internacionalização do Bamerindus como mudança incremental parece contradizer as pesquisas realizadas na área, que consideram a internacionalização basicamente como ocasionadora de mudança estratégica nas organizações, porém vários fatores podem justificar o caráter incremental da mudança no Bamerindus.

$\mathrm{O}$ primeiro fator tem relação com o fato de que a internacionalização no Banco é processo recente. Em geral, os resultados apontados na literatura especializada referem-se a empresas com envolvimento internacional mais prolongado. Por exemplo, Bartlett e Ghoshal (1992), ao mencionarem as mudanças na anatomia, na fisiologia e na psicologia decorrentes do processo de internacionalização, referem-se principalmente a organizações próximas ao seu modelo de empresas transnacionais, com unidades espalhadas em todo o mundo e décadas de experiência no exterior. Assim, o curto tempo de envolvimento internacional do Bamerindus pode justificar a ausência de reorientação estratégica profunda, uma vez que as mudanças culturais são, usualmente, demoradas. Em qualquer organização, é a cultura que lhe confere a identidade (Kanter et al., 1992). Valores e crenças encontram-se profun-

Quadro 2 - Mudança nos valores dos dirigentes no período de 1989 a 1995

\begin{tabular}{|c|c|}
\hline Valores & Análise dos relatórios da administração e mapas causais \\
\hline Postura inovadora, criativa e arrojada & $\begin{array}{l}\text { - propiciou expansão internacional } \\
\text { - foi reforçada pela internacionalização } \\
\text { - não teve sua orientação básica mudada }\end{array}$ \\
\hline Preocupação com clientes/orientação para marketing & $\begin{array}{l}\text { - propiciaram expansão internacional } \\
\text { - foram reforçadas pela internacionalização } \\
\text { - não tiveram suas orientações básicas mudadas }\end{array}$ \\
\hline Importância atribuída à tecnologia & $\begin{array}{l}\text { - propiciou expansão internacional } \\
\text { - foi reforçada pela internacionalização } \\
\text { - não teve sua orientação básica mudada }\end{array}$ \\
\hline Valorização do pessoal & $\begin{array}{l}\text { - propiciou expansão internacional } \\
\text { - foi reforçada pela internacionalização } \\
\text { - não teve sua orientação básica mudada }\end{array}$ \\
\hline Redução de custos/produtividade & - exigiram preocupação maior a partir do Plano Real \\
\hline Postura frente ao risco & - teve reorientação a partir do Plano Real \\
\hline Patriotismo & - não houve alteração na orientação do Banco \\
\hline Fonte: Huff, Narapareddy e Fletcher (1990). & \\
\hline
\end{tabular}


damente arraigados e conferem estabilidade às pessoas e às organizações. Mudanças culturais, portanto, tendem a ser lentas.

A natureza incremental da mudança nos esquemas interpretativos dos dirigentes explica-se, em segundo lugar, pela própria evolução incremental da internacionalização do Bamerindus. O constructo grau de internacionalização reflete um crescimento contínuo mas suave na expansão internacional do Banco. Assim, se não houve saltos no envolvimento internacional, seria de se esperar que os esquemas interpretativos, com maior razão, seguissem uma lógica de mudança incremental.

$\mathrm{O}$ terceiro aspecto que poderia justificar a natureza incremental da mudança encontra-se na própria base de valores compartilhados no Bamerindus. Alguns valores assinalados na análise dos relatórios da administração, e depois convalidados nas entrevistas, não se desenvolveram com o processo de internacionalização, mas, pelo contrário, serviram como estímulo e influenciaram o próprio êxito da expansão internacional. Tais valores foram reforçados pela exposição internacional do Banco, em vez de terem sido desenvolvidos a partir da experiência no exterior. Valores como a postura inovadora e criativa, a importância atribuída à tecnologia, a orientação para o marketing e a valorização do pessoal constituem exemplos.

Como se pode observar na literatura especializada, a própria decisão de internacionalizar-se é indicativa de uma base de valores e crenças prévios, na qual se apóia o envolvimento com outros países. Sem essa base, a decisão não se produziria: estruturas e decisões numa organização só se sustentam quando estão em conformidade com valores e crenças compartilhados (Hinings e Greenwood, 1989). Segundo Hatch (1993), práticas, estratégias e decisões organizacionais, para serem implementadas, necessitam do respaldo inicial de alguns valores e crenças aceitos e disseminados na organização.

Se já havia no Bamerindus um sistema de valores favorável à expansão internacional, por que a decisão de se internacionalizar não ocorreu antes? A questão remete a circunstâncias ambientais do contexto institucional brasileiro. Até finais da década de 80, a economia do país era bastante introvertida, e o grau de abertura ao comércio exterior, mínimo. No setor financeiro havia, ainda, o agravante de uma legislação rígida que dificultava a expansão de unidades bancárias para além das fronteiras do país. Assim, a mudança nos ventos da economia a partir de 1990 e o abrandamento na legislação representaram estímulo para a expansão internacional.

Há uma quarta razão que possivelmente explica o impacto incremental da internacionalização sobre os esquemas interpretativos do grupo dirigente do Banco. Esse quarto fator, que contextualiza em nível mais amplo e propicia o encadeamento dos três fatores tratados até aqui, inspira-se nos marcos da teoria institucional (Scott e Meyer, 1994). O desempenho de uma organização está também condicionado pelo contexto institucional que ela tem como referência; tal contexto pode ser local, regional, nacional ou internacional (Machado-da-Silva e Fonseca, 1996a). No caso do Bamerindus (e, de certo modo, de todo o setor bancário no país), parece haver ênfase no contexto nacional, o que se pode explicar pelas características peculiares do sistema financeiro brasileiro que tornavam o contexto internacional uma realidade distante. Aspectos como as altas taxas de inflação, a constante intervenção do Governo na economia, o caráter introvertido do mercado brasileiro e a própria proibição a bancos estrangeiros de operarem no país funcionaram como buffers (ou amortecedores) que retardaram a transferência do aprendizado internacional para as operações domésticas. Dessa forma, os padrões de referência do contexto institucional nacional impuseram-se como fatores legitimadores. Essa interpretação é coerente com a análise constante de diversos estudos realizados por Machado-da-Silva e Fonseca (1995, 1996a, 1996b).

O caráter incremental da mudança ocasionada pela internacionalização fica bem evidente quando contrastada com o impacto de outra mudança que incidiu sobre o Banco durante o período em estudo. Trata-se da estabilização da economia decorrente do Plano Real, implantado a partir de maio de 1994.

A estabilização econômica representou fator de grande turbulência ambiental para os bancos e, em particular, para o Bamerindus. Habituado a uma economia inflacionária, o Banco tinha como estratégia conseguir uma massa de recursos suficientemente grande para ser emprestada ao Governo, obter altos retornos especulativos e aplicá-los na expansão da rede de agências. $O$ consequiente aumento na capilaridade da rede possibilitava o crescimento na captação, que era novamente emprestada ao Governo, reiniciando o ciclo. Com o controle da inflação, houve uma reviravolta nessa forma de proceder. De uma hora para outra, o Bamerindus teve de rever sua estratégia de mercado, enfatizar operações de crédito, preocupar-se com eficiência e produtividade, aspectos pouco considerados, ou no limite dispensáveis, nos tempos de inflação.

A estabilização foi ocasião de crise para grande parte dos bancos nacionais. O Bamerindus, para contornála, implementou, em dezembro de 1995, uma reestruturação patrimonial no grupo e, em março de 1996, uma reestruturação organizacional, com a troca de líderes na alta administração. Aumentou sua preocupação com a 
eficiência, reorientou suas atividades para o crédito e enfatizou a atuação como banco de varejo. Tais mudanças, de caráter estratégico, trazem à tona algumas características dos esquemas interpretativos que o processo de internacionalização não havia afetado. É possível considerar, no caso em tela, que a reestruturação não resultou do aprofundamento no envolvimento internacional, mas das pressões para reduzir custos em face da nova configuração ambiental.

É razoável que a internacionalização tenha propiciado ao Bamerindus o contato com instituições bancárias internacionais, cuja orientação para a eficiência, a produtividade e a postura quanto ao risco (manifestada de modo especial em operações como crédito) são decisivas para sobreviver no ambiente concorrencial. Além disso, era previsível que o regime inflacionário na economia brasileira não duraria indefinidamente, devido à estabilização monetária dos países vizinhos, à intenção explícita do Governo e à opinião de especialistas. No entanto, entre a implantação do Plano Real e a reorientação estratégica do Bamerindus, passaram-se quase dois anos. Cabe perguntar, portanto, por que o aprendizado decorrente da internacionalização não foi incorporado antes do Plano Real ou, quando muito, imediatamente após sua implantação.

Três razões, de certo modo relacionadas, sugerem possível resposta à questão: a) a tendência de as organizações persistirem em estratégias passadas, ainda que ocorram mudanças no ambiente; b) a estabilidade dos esquemas interpretativos e das estruturas organizacionais; e c) o contexto institucional de referência da organização.

Estudos na área de análise organizacional vêm demonstrando que as organizações tendem a manter estratégias passadas bem-sucedidas, mesmo quando mudam as circunstâncias ambientais. A persistência no comportamento passado, segundo Milliken e Lant (1991), decorre tanto de reservas financeiras como de reservas psicológicas. As reservas financeiras auxiliam a manutenção das estratégias na medida em que, geralmente, o sucesso anterior proporciona margens que permitem a sobrevivência da empresa por algum tempo nas novas condições (tempo suficiente para os dirigentes pensarem que as dificuldades são temporárias). As reservas psicológicas levam os dirigentes a supor que serão capazes de superar sozinhos quaisquer obstáculos que se apresentem.

Hinings e Greenwood (1989) afirmam que a estabi- lidade dos esquemas interpretativos e das estruturas organizacionais tende a atrasar as reorientações estratégicas. Três fatores contribuem para tanto: a monitoração seletiva; a tendência ao adiamento até um ponto em que os custos de não implementar a mudança sejam maiores que os de implementá-la; e as disputas políticas por recursos escassos na organização.

No âmbito da teoria institucional, o ritmo de assimilação do aprendizado internacional pode ser explicado, por um lado, mediante a noção de contexto institucional de referência (internacional, nacional, regional e local) e, por outro, com base nos conceitos de ambientes técnicos e ambientes institucionais (Machado-da-Silva e Fonseca, 1996a). Os ambientes técnicos caracterizam-se pela orientação para a competitividade, de acordo com a abordagem econômica, enfatizando aspectos como a qualidade e a quantidade dos resultados. Os ambientes institucionais compreendem as regras e os procedimentos que proporcionam legitimidade às organizações.

No caso do Bamerindus, as três razões apontadas parecem ter contribuído, de maneira inter-relacionada, para o adiamento da reorientação estratégica. Em primeiro lugar, a desconfiança com relação à efetividade do Plano Real e a existência de reservas financeiras e psicológicas. Em segundo, o alto custo da mudança (adiada até que os custos da não-mudança se tornassem muito altos). Em terceiro, a força do ambiente institucional brasileiro, que convidava as organizações bancárias a pautar suas estratégias a partir da referência ao âmbito de atuação nacional, desconsiderando, portanto, estratégias de organizações que atuam em outros contextos sob o pretexto de que a realidade lá fora não se aplica ao país. Assim, por maiores que fossem as solicitações do ambiente técnico em prol de maior eficiência, as pressões legitimadoras do ambiente institucional nacional acabaram prevalecendo como norma de conduta mais segura.

A internacionalização, ao contrário da estabilização econômica, não representou, no curto prazo, nenhuma ruptura ou reorientação fundamental no Bamerindus e nas formas de interpretação vigentes. O aprendizado disponibilizado pelo processo de internacionalização incidiu no Banco de forma gradativa, primeiro sobre a própria unidade internacional, depois sobre as 
demais. Daí o caráter de ajustamento da internacionalização no período limitado de tempo abrangido pela presente pesquisa.

A natureza incremental do processo de internacionalização fica ainda mais evidente quando se considera a ausência de reorientação nos valores e crenças compartilhados pelos dirigentes do Bamerindus: por um lado, porque os valores coerentes com a orientação internacional tiveram, ao que parece, ajuste incremental ao serem confirmados pela experiência no exterior; por outro lado, valores condicionados pelo contexto institucional de referência também não se transformaram significativamente durante o processo de internacionalização perante as dificuldades impostas pelo forte contexto institucional de referência do Banco, ou seja, o ambiente nacional.

A partir do exposto, poder-se-ia pressupor que, se efetivamente o aprendizado gerado com a experiência internacional tivesse sido incorporado profundamente pelo Bamerindus, as mudanças de estratégia após a estabilização econômica não teriam demorado tanto, para serem, depois, tão traumáticas e emergenciais.
No entanto, é possível que a estabilização econômica abra caminho para uma incorporação efetiva do aprendizado de fora do país em futuro próximo e, portanto, permita ao processo de internacionalização atuar como mudança de caráter estratégico. O Plano Real aproximou os contextos institucionais brasileiro e internacional. Enquanto havia no país um contexto diferenciado, tornava-se difícil a assimilação da experiência do exterior. Nas novas condições, a transferência do aprendizado parece tornar-se mais favorável.

O caso da expansão internacional do Bamerindus é sugestivo na medida em que demonstra que o impacto da internacionalização sobre uma organização não pode ser desvinculado do contexto institucional de referência dessa organização. O contexto institucional estabelece parte importante das condições mediante as quais a realidade é interpretada. Desse modo, se o aprendizado internacional (e, possivelmente, qualquer forma de aprendizado) não encontra respaldo no contexto institucional de referência da organização, dificilmente será assimilado no ritmo e nos níveis desejáveis. $\bigcirc$

\section{REFERÊNCIAS BIBLIOGRÁFICAS}

ARRUDA, C. A., GOULART, L., BRASIL, H. V. Estratégia de internacionalização: competitividade e incrementalismo. In: Encontro Anual da ANPAD, 8, 1994, Curitiba. Anais. Curitiba: ANPAD, 1994. v.8, p.312-26.

BARR, P. S., STIMPERT, J. L., HUFF, A. S. Cognitive change, strategic action, and organizational renewal. Strategic Management Journal, v.13, p.15-36, 1992.

BARTLETT, C. A., GHOSHAL, S. Gerenciando empresas no exterior: a solução transnacional. São Paulo: Makron Books, 1992

DERESKY, H. International management. New York: HarperCollins Publishers, 1994.

GOULART, L., ARRUDA, C. A., BRASIL, H. V. A evolução da dinâmica de internacionalização. Revista Brasileira de Comércio Exterior, n.41, p.31-41, out./dez. 1994.

HATCH, M. J. The dynamics of organizational culture Academy of Management Review, v.18, n.4, p.657-93, 1993.

HININGS, C. R., GREENWOOD, R. The dynamics of strategic change. New York: Basil Blackwell, 1989.
HUFF, A. S., NARAPAREDDY, V., FLETCHER, K. E. Coding the causal association of concepts. In: HUFF, A. S. (Ed.). Mapping strategic thought. Chichester: Wiley and Sons, 1990.

JOHANSON, J., VAHLNE, J. E. The mechanism of internationalization. International Marketing Review, v.7, p.1124, 1990.

KANTER, R. M. STEIN, B. A. JICK, T. D. The challenge of organizational change: how companies experience it and leaders guide it. New York: The Free Press, 1992.

MACHADO-DA-SILVA, C. L., FONSECA, V. Homogeneização e diversidade organizacional. In: Encontro Anual da ANPAD, 7, 1993, Salvador. Anais... Salvador: ANPAD, 1993. v.9, p.147-59.

MACHADO-DA-SILVA, C. L., FONSECA, V. Configuração estrutural da indústria calçadista de Novo Hamburgo. In: FENSTERSEIFER, J. E. (Org.). O complexo calçadista em perspectiva: tecnologia e competitividade. Porto Alegre: Ortiz, 1995.

MACHADO-DA-SILVA, C. L., FONSECA, V. Competitividade organizacional: uma tentativa de reconstrução analítica. In: Encontro Anual da ANPAD, 20, 1996, Angra dos Reis. Anais.. Angra dos Reis: ANPAD, 1996a. v. Organizações II, p.207-22.
MACHADO-DA-SILVA, C. L., FONSECA, V. Patterns of meaning: institutionalization and circumstances In: PALMER, G., CLEGG, S. (Eds.). Constituting management markets, meanings, and identities. Berlin: Walter de Gruyter, 1996b.

MELIN, L. Internationalization as a strategy process Strategic Management Journal, v.13, p.99-118, 1992.

MILLIKEN, F. J., LANT, T. K. Past performance, interpretations, and strategic choice. In: SHRIVASTAVA P., HUFF, A., DUTTON, J. (Eds.). Advances in strategic management. Greenwich: Jai Press, v.7, 1991.

PERLMUTTER, H. The tortuous evolution of the multinational corporation. Columbia Journal of World Business, p.9-18, Jan./Feb. 1969.

SCOTT, W. R., MEYER, J. W. Institutional environments and organizations: structural complexity and individualism. Thousand Oaks: Sage Publications, 1994.

SULLIVAN, D. Measuring the degree of internationalization of a firm. Journal of International Business Studies, p.325-42, second quarter 1994.

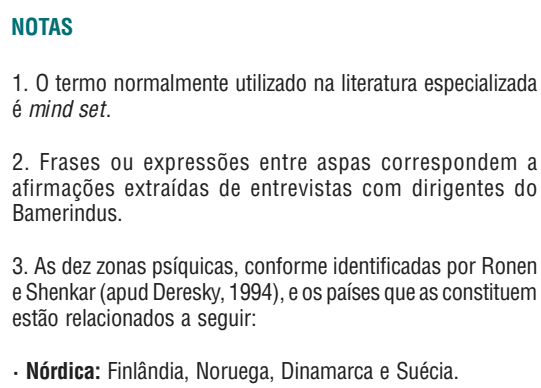

3. As dez zonas psíquicas, conforme identificadas por Ronen e Shenkar (apud Deresky, 1994), e os países que as constituem estão relacionados a seguir:

Nórdica: Finlândia, Noruega, Dinamarca e Suécia.

- Germânica: Áustria, Alemanha e Suíça.

- Anglo: Estados Unidos, Canadá, Austrália, Reino Unido, Irlanda e África do Sul.

- Europa Latina: França, Bélgica, Itália, Portugal, Espanha e Luxemburgo.

- América Latina: Argentina, Venezuela, México, Chile, Peru e Colômbia.

- Extremo Oriente: Cingapura, Malásia, Hong Kong, Vietnã do
Sul, Filipinas, Indonésia, Taiwan (Formosa) e Tailândia.

- Árabe: Emirados Árabes Unidos, Arábia Saudita, Kuwait, Omã, Abu-Dhabi e Bahrein.

- Oriente Próximo: Turquia, Irã e Grécia.

- Independentes: Brasil, Japão, Índia e Israel.

- Outros: Bermudas, Grand Cayman, Bahamas, Panamá

Não se atribuiu pontuação para as unidades do país-sede. 